\title{
No-Tension Sensor Closed-Loop Control Method with Adaptive PI Parameters for Two-Motor Winding System
}

\author{
Zhiqiang Wang $\left(\mathbb{D},{ }^{1}\right.$ Haibao Nan, ${ }^{2}$ Tingna Shi, ${ }^{2}$ Qiang Geng, ${ }^{1}$ and Changliang Xia ${ }^{1,2}$ \\ ${ }^{1}$ Tianjin Key Laboratory of Advanced Technology of Electrical Engineering and Energy, Tianjin Polytechnic University, \\ Tianjin 300387, China \\ ${ }^{2}$ School of Electrical Engineering and Automation, Tianjin University, Tianjin 300072, China
}

Correspondence should be addressed to Zhiqiang Wang; wangzhq@tju.edu.cn

Received 7 February 2017; Revised 13 July 2017; Accepted 9 August 2017; Published 16 January 2018

Academic Editor: Xinggang Yan

Copyright (C) 2018 Zhiqiang Wang et al. This is an open access article distributed under the Creative Commons Attribution License, which permits unrestricted use, distribution, and reproduction in any medium, provided the original work is properly cited.

\begin{abstract}
In a winding system, it is very important to control the tension precisely. Based on the process of rewinding and unwinding, a sensorless tension control method with PI parameters of adaptive speed controllers is proposed in this paper. According to the principle of torque balance, a tension observer is designed to replace the tension sensor, and the observed value instead of the measured value of tension is used as feedback. Then the measurement delay caused by tension sensor is reduced. For the time-variable inertia, Landau discrete-time recursive algorithm is used to estimate the inertias of the rewind and unwind motors. Moreover, the estimated inertias are used to adjust the PI parameters of the speed controllers. As the tension control system has the ability to adapt to the change of inertia, its dynamic performance is improved to some extent. In addition, the proposed sensorless tension control method is simple and easy to implement, which only uses the current and speed signals of the motors without any additional hardware needed. At last, the feasibility and effectiveness of the proposed method are verified by the experimental results.
\end{abstract}

\section{Introduction}

Tension control system is widely applied in industrial fields where high precision and productivity are required, including printing, textile, chemical fiber, and metallurgy. Improper control of tension will result in the winding material fracture, wrinkle, deviation, and so on [1-3]. Currently, there are three ways to control the tension in industrial application: openloop control, direct closed-loop control, and indirect closedloop control [4-7]. Since the precision is lower in openloop control method, the direct closed-loop control methods are commonly used in actual industry. However, tension sensors need to be installed in direct closed-loop control method. Besides the high price and the existing delay, the signal of the tension sensor is also very weak, which is easily interfered by the environment, so this method cannot be applied in some special occasions. Therefore, if a tension observer can be designed to replace the tension sensor and the same control performance can be obtained compared with the direct closed-loop control method, it will be of great significance in tension control field.

Domestic and foreign scholars have put forward a variety of implementations about tension control without tension sensor in winding systems. Valenzuela et al. at the University of Concepcion, Chile, proposed a control scheme without tension sensor in papermaking system. Two new tension estimators are developed for a two-drum electric-brakinggenerator production winder that are based on unwinding and rewinding variables, respectively, with the essential dynamic, friction, and inertial variation effects considered in the scheme [8-11]. Lynch from the University of Alberta in Canada exploited linear time-varying error dynamics to design a reduced-order, nonlinear tension observer. Exponential stability of the error dynamics is also demonstrated in this method, and the performance of the estimator is experimentally compared with two competing designs on real web-handing machine [12]. Song and Sul proposed a tension control method with tension observer, which is used 
in continuous strip processing line, including the acceleration torque. As this scheme directly controls torque current of motors, faster dynamic response can be obtained in case of linear speed acceleration or deceleration [13, 14]. In [15], a sliding-mode (SM) feedback linearization control system is designed for a multimotor web-winding system. This method consists of a SM velocity controller and two SM tension controllers. Two tension observers are suggested to eliminate the need of tension sensors in a web-winding system. Moreover, the effectiveness and capability of the proposed control strategy are verified by simulation. In the field of multimotor control, sliding-mode variable structure control method is a very effective control algorithm. In [16, 17], the basic principle of the SM method is introduced in detail, and some of the unique problems in the motor control and multimotor control are introduced. In [18], to filter out the measurement noises of velocities and estimate the load torque of motors, an augmented observer is proposed. In [19], a novel data-based hybrid tension estimation and fault diagnosis method is proposed to estimate the unmeasured tension between two neighbouring rolls. The tension error compensation model is designed by applying neural networks principal component regression, and the corresponding tension fault diagnosis method is designed using the estimated tensions. Moreover, the proposed tension estimation and fault diagnosis method is applied to a real continuous annealing process line in a steel-making company.

There are many factors that influence the tension control performance in actual industrial production, among which one of the most important is the time-varying inertia [20, 21]. The moment of inertia will change with the radii of the rewind and unwind rolls, which will change with the operation of the system. The performance may further deteriorate if controller parameters are not adjusted properly according to the timevarying inertia. The traditional solution is to estimate the moment of inertia based on speed, thickness, and density of the winding material and correct the controller parameters using the estimated inertia to achieve the desired control performance. However, in some instances the density and thickness are unknown or vary with the humidity, temperature, and other external environment changes. Therefore, the traditional method of estimating the inertia cannot be used in some special occasions.

This paper is organized as follows. In Section 2, the dynamic model is set up, and the traditional tension control structure is analyzed. In Section 3, a new tension control strategy without tension sensor is proposed. For the identification of tension, a reduced-order observer is designed to observe the tension, which eliminates the use of tension sensor. For the time-varying inertia, Landau discrete-time recursive algorithm is adopted to estimate the inertia, and the estimated inertias are used to correct the PI parameters of speed controllers, so that the tension control system can still have good dynamic performance even if the inertia changes substantially. At last, a series of comparative experiments are conducted, and the feasibility and effectiveness of the proposed method are verified by the experimental results.

\section{The Description and Modelling of the Winding System}

The tension control system that contains only one tension zone is shown in Figure 1(a). This is the simplest unit of tension control system of multispan. This structure mainly contains rewind roll, unwind roll, tension sensor, controllers, and so on. Then, the changes of radii and inertia of the rewind and unwind rolls are analyzed. According to the relationship of the volume diameter, thickness of the winding material, and the rotation angle, the following equation can be obtained:

$$
\begin{aligned}
& R_{\mathrm{r}}(t) \approx R_{\mathrm{ro}}+\frac{\theta_{\mathrm{r}}}{2 \pi} h, \\
& R_{\mathrm{u}}(t) \approx R_{\mathrm{uo}}-\frac{\theta_{\mathrm{u}}}{2 \pi} h,
\end{aligned}
$$

where $R_{\mathrm{r}}$ and $R_{\mathrm{u}}$ are the radii of rewind and unwind rolls, respectively; $R_{\mathrm{ro}}$ and $R_{\mathrm{uo}}$ are the initial radii of rewind and unwind rolls, respectively; $\theta_{\mathrm{r}}$ and $\theta_{\mathrm{u}}$ represent the rotation angles of rewind and unwind rolls, respectively; and $h$ represents the thickness of the winding material.

After differentiation of (1), the change rates of the volume diameters of rewind and unwind rolls are obtained

$$
\begin{aligned}
& \frac{\mathrm{d} R_{\mathrm{r}}(t)}{\mathrm{d} t}=\frac{\omega_{\mathrm{r}} h}{2 \pi}, \\
& \frac{\mathrm{d} R_{\mathrm{u}}(t)}{\mathrm{d} t}=-\frac{\omega_{\mathrm{u}} h}{2 \pi},
\end{aligned}
$$

where $\omega_{\mathrm{r}}$ and $\omega_{\mathrm{u}}$ are the angular velocity of rewind and unwind rolls, respectively. The inertia of rewind and unwind rolls can be expressed as follows [19]:

$$
\begin{aligned}
& J_{\mathrm{r}}(t)=J_{\mathrm{ro}}+\frac{\pi}{2} \rho b\left(R_{\mathrm{r}}^{4}-R_{\mathrm{ro}}^{4}\right), \\
& J_{\mathrm{u}}(t)=J_{\mathrm{uo}}+\frac{\pi}{2} \rho b\left(R_{\mathrm{u}}^{4}-R_{\mathrm{uo}}^{4}\right) .
\end{aligned}
$$

In (3), $J_{\mathrm{r}}(t)$ and $J_{\mathrm{u}}(t)$ represent the inertias of rewind and unwind rolls, respectively; $J_{\text {ro }}$ and $J_{\text {uo }}$ represent the inertias when the rewind and unwind rolls are empty; $\rho$ is the density of the winding material; and $b$ is the width of the winding material. After differentiation of (3), the change rate of the inertias of rewind and unwind rolls are obtained

$$
\begin{aligned}
& \frac{\mathrm{d} J_{\mathrm{r}}(t)}{\mathrm{d} t}=2 \pi \rho b R_{\mathrm{r}}^{3} \frac{\mathrm{d} R_{\mathrm{r}}(t)}{\mathrm{d} t}, \\
& \frac{\mathrm{d} J_{\mathrm{u}}(t)}{\mathrm{d} t}=2 \pi \rho b R_{\mathrm{u}}^{3} \frac{\mathrm{d} R_{\mathrm{u}}(t)}{\mathrm{d} t} .
\end{aligned}
$$

According to the torque balance principle and the Karnopp friction model used in this manuscript [22], then the dynamic equations can be expressed as

$$
\begin{aligned}
& \frac{\mathrm{d}}{\mathrm{d} t}\left(J_{\mathrm{r}} \omega_{\mathrm{r}}\right)=T_{\mathrm{er}}-F R_{\mathrm{r}}-T_{\mathrm{fr}}-B_{\mathrm{r}} \omega_{\mathrm{r}}, \\
& \frac{\mathrm{d}}{\mathrm{d} t}\left(J_{\mathrm{u}} \omega_{\mathrm{u}}\right)=T_{\mathrm{eu}}+F R_{\mathrm{u}}-T_{\mathrm{fu}}-B_{\mathrm{u}} \omega_{\mathrm{u}},
\end{aligned}
$$




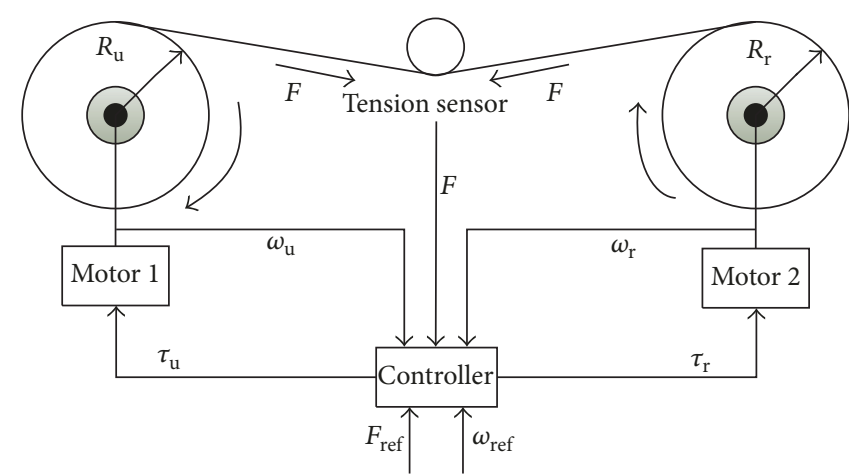

(a)

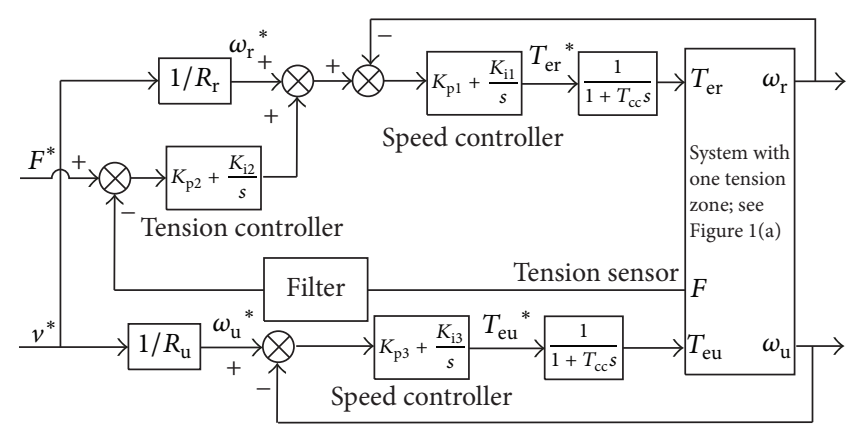

(b)

FIgURE 1: Winding system with two motors. (a) Tension control system with two motors; (b) tension controller with tension sensor.

where $T_{\mathrm{er}}$ and $T_{\mathrm{eu}}$ are the output torque of the rewind and unwind rolls, respectively; $F$ is the tension of the system; $B_{\mathrm{r}}$ and $B_{\mathrm{u}}$ are viscous friction coefficients; and $T_{\mathrm{fr}}$ and $T_{\mathrm{fu}}$ are coulomb friction. The viscous friction coefficients and coulomb friction are obtained by measurements in experiment at the offline state. During the operation, the friction torque changes over time, with degradation of bearings, lubrication, and so on. Accurate estimation or online measurement of the friction is actually very difficult and is impossible in real-world industrial winders. However, the change of the friction with degradation of bearings and lubrication is small and very slow, so viscous friction coefficients and coulomb friction can be considered constant value during the operation.

Substituting (1) (4) into (5) and rearranging (5), the following equation can be obtained:

$$
\begin{aligned}
F \cdot\left(R_{\mathrm{ro}}+\frac{\theta_{\mathrm{r}}}{2 \pi} h\right)= & T_{\mathrm{er}}-T_{\mathrm{fr}}-B_{\mathrm{r}} \omega_{\mathrm{r}} \\
& -2 \pi \omega_{\mathrm{r}} \rho b R_{\mathrm{r}}^{3} \frac{\mathrm{d} R_{\mathrm{r}}(t)}{\mathrm{d} t} \\
& -\left[J_{\mathrm{ro}}+\frac{\pi}{2} \rho b\left(R_{\mathrm{r}}^{4}-R_{\mathrm{ro}}^{4}\right)\right] \\
& \cdot \frac{\mathrm{d} \omega_{\mathrm{r}}}{\mathrm{d} t}, \\
F \cdot\left(R_{\mathrm{uo}}-\frac{\theta_{\mathrm{u}}}{2 \pi} h\right)= & -T_{\mathrm{eu}}+T_{\mathrm{fu}}+B_{\mathrm{r}} \omega_{\mathrm{u}} \\
& +2 \pi \omega_{\mathrm{u}} \rho b R_{\mathrm{u}}^{3} \frac{\mathrm{d} R_{\mathrm{u}}(t)}{\mathrm{d} t} \\
& +\left[J_{\mathrm{uo}}+\frac{\pi}{2} \rho b\left(R_{\mathrm{u}}^{4}-R_{\mathrm{uo}}^{4}\right)\right] \\
& \cdot \frac{\mathrm{d} \omega_{\mathrm{u}}}{\mathrm{d} t} .
\end{aligned}
$$

According to the analysis above, the size of the tension is influenced by many factors, such as the density and width of the winding material, volume diameter, friction coefficient, and velocity. Variation in any of the aforementioned factors will impose a certain effect on the tension. Therefore, tension control system is a multivariable, nonlinear, strong coupling control system. To accurately control the tension, the impact of various factors must be considered.

Presently, tension sensor is commonly used in direct closed-loop tension control structure among the actual industrial production. The structure is shown in Figure 1(b). The unwind motor is used to control the entire system speed and the rewind motor is used to control the tension. In Figure $1(\mathrm{~b}), v^{*}$ represents the reference velocity and $T_{c c}$ corresponds to the time constant of the first-order delay of the current controller.

\section{The Design of No-Tension Sensor Control System with Adaptive PI Parameters}

3.1. The Design of the Tension Observer. From the dynamic equations of rewind and unwind motors, it is easy to find that the change of tension is reflected in the torque elements of the rewind and unwind rolls. Therefore, a tension observer can be implemented based on the drive torque components that is related to the tension zone. The tension could be obtained through analyzing the dynamic equation of the rewind motor or unwind motor, and they should be equal in theory. The rewind roll is taken as an example in the following analysis.

Taking the tension $F$ as a state variable, as the change rate of tension is far less than the sampling frequency of the controller, the tension can be considered as a constant value in a control period; that is to say,

$$
\frac{\mathrm{d} F}{\mathrm{~d} t}=0 .
$$

Since the change rate of inertia is much less than the change rate of angular velocity in the tension control system, (5) can be approximated by

$$
\begin{aligned}
& \frac{\mathrm{d}}{\mathrm{d} t}\left(J_{\mathrm{r}} \omega_{\mathrm{r}}\right) \approx J_{\mathrm{r}} \frac{\mathrm{d} \omega_{\mathrm{r}}}{\mathrm{d} t} \approx T_{\mathrm{er}}-F R_{\mathrm{r}}-T_{\mathrm{fr}}-B_{\mathrm{r}} \omega_{\mathrm{r}}, \\
& \frac{\mathrm{d}}{\mathrm{d} t}\left(J_{\mathrm{u}} \omega_{\mathrm{u}}\right) \approx J_{\mathrm{u}} \frac{\mathrm{d} \omega_{\mathrm{u}}}{\mathrm{d} t} \approx T_{\mathrm{eu}}+F R_{\mathrm{u}}-T_{\mathrm{fu}}-B_{\mathrm{u}} \omega_{\mathrm{u}} .
\end{aligned}
$$


According to (7) and the first equation of (8), the dynamic state equation of the rewind motor can be obtained as

$$
\begin{aligned}
& \dot{\mathbf{x}}=\mathbf{A x}+\mathbf{B u}, \\
& \mathbf{y}=\mathbf{C} \mathbf{x}
\end{aligned}
$$

where $\mathbf{x}=\left[\begin{array}{ll}\omega_{\mathrm{r}} & F\end{array}\right]^{\mathrm{T}}$ is state variable; $\mathbf{u}=\left[T_{\mathrm{er}}-T_{\mathrm{fr}}\right]$ is input signal; $\mathbf{y}=\left[\omega_{\mathrm{r}}\right]$ is the output signal; $\mathbf{A}=\left[\begin{array}{cc}-B_{\mathrm{r}} / J_{\mathrm{r}} & -R_{\mathrm{r}} / J_{\mathrm{r}} \\ 0 & 0\end{array}\right] ; \mathbf{B}=$ $\left[\begin{array}{c}1 / J_{\mathrm{r}} \\ 0\end{array}\right]$; and $\mathbf{C}=\left[\begin{array}{ll}1 & 0\end{array}\right]$.

The necessary and sufficient condition for system (9) to have an observer and be able to choose the observer poles arbitrarily is the observability of system (9). The observability matrix of (9) is

$$
\mathbf{Q}=\left[\begin{array}{c}
\mathbf{C} \\
\mathbf{C A}
\end{array}\right]=\left[\begin{array}{cc}
1 & 0 \\
-\frac{B_{\mathrm{r}}}{J_{\mathrm{r}}} & -\frac{R_{\mathrm{r}}}{J_{\mathrm{r}}}
\end{array}\right] .
$$

As $|\mathbf{Q}|=-R_{\mathrm{r}} / J_{\mathrm{r}} \neq 0$, the matrix $\operatorname{rank}$ of $\mathbf{Q}$ is $\operatorname{rank} \mathbf{Q}=2$, so system (9) is observable.

According to the idea of reduced-order state observer in modern control theory [23], if we take the angular velocity of the rewind motor as a correction variable in the tension observer, the tension observer can be expressed as

$$
\begin{aligned}
& \dot{\hat{\mathbf{x}}}=\mathbf{A} \widehat{\mathbf{x}}+\mathbf{B u}+\mathbf{K}(\mathbf{y}-\widehat{\mathbf{y}}), \\
& \widehat{\mathbf{y}}=\mathbf{C} \widehat{\mathbf{x}},
\end{aligned}
$$

where $\widehat{\mathbf{x}}=\left[\begin{array}{ll}\widehat{\omega}_{\mathrm{r}} & \widehat{F}\end{array}\right]^{\mathrm{T}}$ is the state variable of the observer; $\widehat{\mathbf{y}}=$ $\left[\widehat{\omega}_{\mathrm{r}}\right]$ is the output of the observer; and $\mathbf{K}=\left[\begin{array}{ll}k_{1} & k_{2}\end{array}\right]^{\mathrm{T}}$ is the feedback gain.

From (9) and (11), the observation error can be obtained as

$$
\begin{aligned}
\dot{\mathbf{x}}-\dot{\hat{\mathbf{x}}} & =\mathbf{A} \mathbf{x}+\mathbf{B u}-[(\mathbf{A}-\mathbf{K C}) \widehat{\mathbf{x}}+\mathbf{B u}+\mathbf{K y}] \\
& =(\mathbf{A}-\mathbf{K C})(\mathbf{x}-\widehat{\mathbf{x}}) .
\end{aligned}
$$

The characteristic of (12) can be expressed as follows:

$$
\operatorname{det}[s \mathbf{I}-(\mathbf{A}-\mathbf{K C})]=s^{2}+\left(\frac{B_{\mathrm{r}}}{J_{\mathrm{r}}}+k_{1}\right) s-\frac{R_{\mathrm{r}}}{J_{\mathrm{r}}} k_{2}=0 .
$$

Through the stability conditions of state observer, it is known that if an appropriate matrix $\mathbf{K}$ is selected to make all roots of the characteristic equation have negative real parts, the following equation is obtained:

$$
\lim _{t \rightarrow \infty}(\mathbf{x}-\widehat{\mathbf{x}})=0
$$

The key to observe the state variables accurately is the selection of $\mathbf{K}$ matrix, which is independent of the state variable $\mathbf{x}$ and the input $\mathbf{u}$. Assuming that the desired two observer eigenvalues are $\alpha$ and $\beta$, the expected characteristic equation can be obtained as

$$
s^{2}-(\alpha+\beta) s+\alpha \cdot \beta=0
$$

According to (13) and (15), the $\mathbf{K}$ matrix can be selected as

$$
\begin{aligned}
& k_{1}=-(\alpha+\beta)-\frac{B_{\mathrm{r}}}{J_{\mathrm{r}}}, \\
& k_{2}=-\alpha \beta \frac{J_{\mathrm{r}}}{R_{\mathrm{r}}} .
\end{aligned}
$$

The positions of the poles $\alpha$ and $\beta$ should be chosen according to the desired characteristics of the system. The tension observer will be asymptotically stable as long as the poles $\alpha$ and $\beta$ have negative real parts. $\alpha=\beta=-6$ is adopted in this paper.

The observer input signal coulomb friction $T_{\mathrm{fr}}$ is obtained by repeated measurements in experiment at the offline state; the electromagnetic torque is obtained by the current of qaxis; it can be expressed as follows:

$$
T_{\mathrm{er}}=K_{\mathrm{T}} \cdot i_{\mathrm{qr}},
$$

where $K_{\mathrm{T}}$ is the torque coefficient of rewind motor and $i_{\mathrm{qr}}$ is the q-axis current of rewind motor.

3.2. Identification of the Inertia. The moment of inertia will change with the radii of the rewind and unwind rolls, which will change with the operation of the system. Therefore, if the controller parameters are not corrected according to the inertia, the dynamic performance of the tension control system will deteriorate. The conventional method is to use (3) to estimate the inertia approximately, for which the knowledge of the density, thickness, and other variables of the winding material is required. However, these variables are unknown or difficult to obtain by measurement in some cases. In this paper, Landau discrete-time recursive algorithm is used to observe the inertias [24]. The main idea of Landau algorithm is to use the equation with the unknown parameter as the reference model and the equation without the unknown parameter as the adjustable model. The two models have the same physical input and output. Then, the parameters of the adjustable model are adjusted in real time by the error of the output of the two models until the difference between the two is no longer further reduced, thus realizing the output of the adjustable model's output tracking control object [25]. Thus the inertias can be obtained accurately even under the condition that the density, thickness, and other parameters of the winding material are unknown. Taking rewind roll as an example for analysis and ignoring friction coefficient, (8) can be described as follows:

$$
\begin{aligned}
\omega_{\mathrm{r}}(k)= & \omega_{\mathrm{r}}(k-1) \\
& +\frac{T_{\mathrm{s}}}{J_{\mathrm{r}}}\left[T_{\mathrm{er}}(k-1)-R_{\mathrm{r}}(k-1) F(k-1)\right], \\
\omega_{\mathrm{r}}(k-1)= & \omega_{\mathrm{r}}(k-2) \\
& +\frac{T_{\mathrm{s}}}{J_{\mathrm{r}}}\left[T_{\mathrm{er}}(k-2)-R_{\mathrm{r}}(k-2) F(k-2)\right] .
\end{aligned}
$$

In (18), $T_{\mathrm{s}}$ is the control period. Since the sampling time is very short, it can be assumed that the change periods of 
tension and radii are much greater than the speed calculation period; then the following equation can be obtained:

$$
R_{\mathrm{r}}(k-1) F(k-1) \approx R_{\mathrm{r}}(k-2) F(k-2) .
$$

By the subtraction of the two equations in (18), the following equation is obtained:

$$
\omega_{\mathrm{r}}(k)=2 \omega_{\mathrm{r}}(k-1)-\omega_{\mathrm{r}}(k-2)+b U(k-1) .
$$

In (20), $U(k-1)=T_{\mathrm{er}}(k-1)-T_{\mathrm{er}}(k-2) ; b=T_{\mathrm{s}} / J_{\mathrm{r}} ;$ if we take (20) as the reference model, the adjustable model expressed in the a priori form can be described as follows, namely, the estimated angular speed in the $k$ th control cycle.

$$
\begin{aligned}
\widehat{\omega}_{\mathrm{r}}^{0}(k)= & 2 \omega_{\mathrm{r}}(k-1)-\omega_{\mathrm{r}}(k-2) \\
& +\widehat{b}(k-1) U(k-1) .
\end{aligned}
$$

In (21), $\widehat{b}(k-1)=T_{\mathrm{s}} / \widehat{J}_{\mathrm{r}}$ is the variable to be identified and $\widehat{\omega}_{\mathrm{r}}^{0}(k)$ is the adjustable model expressed in the a priori form; the priori error can be expressed as follows:

$$
e_{0}(k)=\omega_{\mathrm{r}}(k)-\widehat{\omega}_{\mathrm{r}}^{0}(k) .
$$

According to Landau discrete-time recursive algorithm, the adaptive rate of inertia can be expressed as

$$
\widehat{b}(k)=\widehat{b}(k-1)+\gamma \frac{U(k-1)}{1+\gamma U^{2}(k-1)} e_{0}(k) .
$$

In (23), $\gamma$ represents the adaptive gain; since $T_{s}$ is a constant value, the inertia $\widehat{J}_{\mathrm{r}}$ can be calculated through the observed value $\widehat{b}(k)$.

According to the basic principle of Landau algorithm, it can be seen that changing the value of $\gamma$ can change the convergence speed and precision of $\widehat{b}(k)$. And the higher the adaptive gain, the smaller the convergence time of Landau algorithm. But the jitter amplitude of the result of the moment of inertia identification increases with the increase of the adaptive gain $\gamma$ value. When the value of the adaptive gain is too large, the chattering of the moment of inertia is too severe to be unrecognizable, and the magnitude of the adaptive gain $\gamma$ needs to be compromised between the convergence time and the recognition accuracy. Therefore, the value of the adaptive gain $\gamma$ needs to be compromised between the convergence time and the identification accuracy.

3.3. Structure Diagram of the Proposed Tension Control Method. The control block diagram of the tension control method proposed in this paper is shown in Figure 2(a). It mainly consists of a rewind motor, an unwind motor, a tension observer, and two inertia observers. The rewind and unwind motors are used to drive the winding rolls. The two motors are both surface mounted permanent magnet synchronous motors. Double-closed-loop vector control structure with inner current loop and outer speed loop is adopted in this system. The controllers of current loop, velocity loop, and tension loop are all integral isolated PI regulators. The PI parameters of speed controllers are designed according to the bandwidth related in $[26,27]$.

And the speed signal is obtained by incremental encoder. The tension observer is used to observe the tension, which eliminates the application of tension sensor. The inertia observers are used to observe the inertias of the rewind and unwind motors. Moreover, the observed inertias are used to correct the parameters of speed controllers. Therefore, the tension control system can still have a good dynamic performance even if the inertia changes dramatically.

Then the methods of how to set the PI parameters and how to revise the PI parameters are described. Taking the rewind motor as an example, as can be seen from (8), the inertia of the motor can affect system dynamic performance. The response time of electromagnetic torque is much less than the response time of the mechanical system as to the PMSM Vector Control System. So the dynamic process of the current loop can be ignored when analyzing the speed tracking performance and the disturbance rejection performance. Figure 3 shows the simplified control block diagram of the velocity loop.

In Figure 3, $\omega_{\text {ref }}$ is the reference speed, $T_{\mathrm{L}}=F R_{\mathrm{r}}+T_{\mathrm{fr}}$ is the load torque, and $e_{\omega}$ is the tracking error.

Considering that the friction factor $B_{\mathrm{r}}$ is generally much smaller, therefore, the friction factor $B_{\mathrm{r}}$ is ignored in the subsequent analyses. In this case, the closed-loop transfer function from $\omega_{\text {ref }}$ to $\omega_{\mathrm{r}}$ can be expressed as

$$
G_{\mathrm{io}}(s)=\frac{\omega_{\mathrm{r}}(s)}{\omega_{\mathrm{ref}}(s)}=\frac{k_{\mathrm{vp}}}{J_{\mathrm{r}}} \frac{s+k_{\mathrm{vi}} / k_{\mathrm{vp}}}{s^{2}+\left(k_{\mathrm{vp}} / J_{\mathrm{r}}\right) s+k_{\mathrm{vi}} / J_{\mathrm{r}}},
$$

where $k_{\mathrm{vp}}$ is the proportional gain of the PI controller and $k_{\mathrm{vi}}$ is the integral gain of the PI controller; $k_{\mathrm{vp}}>0, k_{\mathrm{vi}}>0$.

The closed-loop transfer function from $T_{\mathrm{L}}$ to $\omega_{\mathrm{r}}$ can be expressed as

$$
G_{\mathrm{do}}(s)=\frac{\omega_{\mathrm{r}}(s)}{T_{\mathrm{L}}(s)}=-\frac{1}{J_{\mathrm{r}}} \frac{s}{s^{2}+\left(k_{\mathrm{vp}} / J_{\mathrm{r}}\right) s+k_{\mathrm{vi}} / J_{\mathrm{r}}} .
$$

The speed tracking performance and the disturbance rejection performance are good or bad when using PI controller depends on the pole-zero distribution of the transfer function (24) and (25), respectively. As can be seen from (24) and (25), the pole-zero distributions are closely related to $k_{\mathrm{vp}}$ and $k_{\mathrm{vi}}$. The parameters $k_{\mathrm{vp}}$ and $k_{\mathrm{vi}}$ are mainly determined by the dynamic performance index of tension control system. The bandwidth of speed loop can be determined through the speed loop rise time $t_{\mathrm{rc}}$.

$$
\alpha_{\mathrm{s}}=\frac{\ln 9}{t_{\mathrm{rc}}} \approx \frac{2.2}{t_{\mathrm{rc}}} .
$$

If the proportionality coefficient $k_{\mathrm{vp}}$ is set as follows, it can guarantee that the speed loop rise time is less than $t_{\mathrm{rc}}$.

$$
k_{\mathrm{vp}}=\alpha_{\mathrm{s}} J_{0} \text {, }
$$

where $J_{0}$ is the default value of the inertia. 


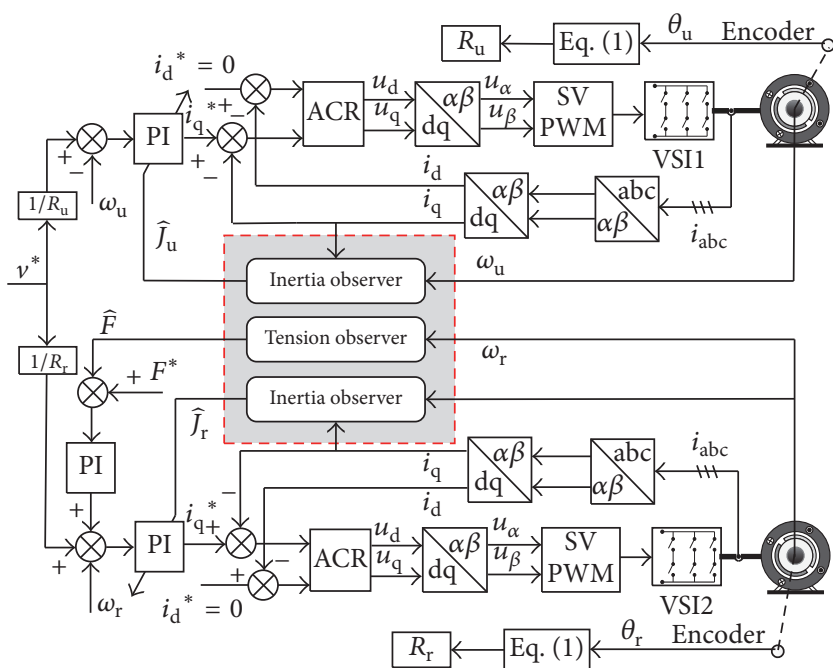

(a)

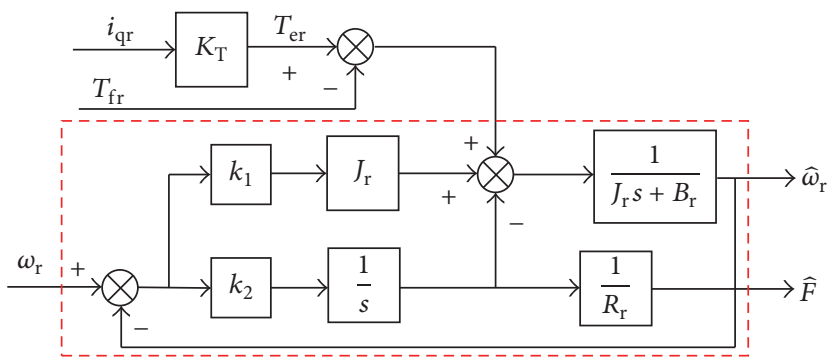

(c)

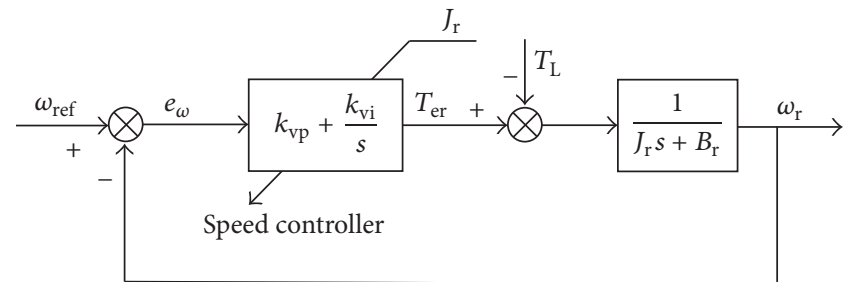

(b)

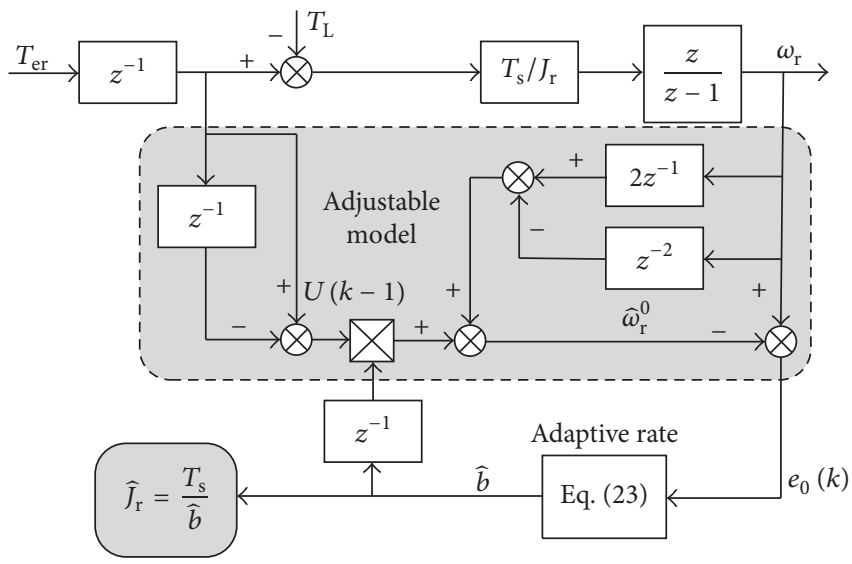

(d)

FIGURE 2: Structure diagram of the proposed tension control method. (a) Structure diagram of the proposed tension control method; (b) simplified control block diagram of the rewind motor velocity loop; (c) block diagram of the tension observer; (d) block diagram of the inertia observer.

The integral coefficient $k_{\mathrm{vi}}$ can be set as

$$
k_{\mathrm{vi}}=\left(\frac{\alpha_{\mathrm{s}}}{2 \zeta}\right)^{2} J_{0} \text {, }
$$

where $\zeta$ is the damping ratio.

Substitute (27) and (28) into (24) and (25); then the following equations are obtained:

$$
\begin{aligned}
G_{\text {io }}(s) & =\frac{\omega_{\mathrm{r}}(s)}{\omega_{\text {ref }}(s)} \\
& =\frac{J_{0}}{J_{\mathrm{r}}} \frac{\alpha_{\mathrm{s}}\left(s+\alpha_{\mathrm{s}} / 4 \zeta^{2}\right)}{s^{2}+\left(J_{0} / J_{\mathrm{r}}\right) \alpha_{\mathrm{s}} s+\left(J_{0} / J_{\mathrm{r}}\right)\left(\alpha_{\mathrm{s}} / 2 \zeta\right)^{2}}, \\
G_{\mathrm{do}}(s) & =\frac{\omega_{\mathrm{r}}(s)}{T_{\mathrm{L}}(s)} \\
& =-\frac{1}{J_{\mathrm{r}}} \frac{s}{s^{2}+\left(J_{0} / J_{\mathrm{r}}\right) \alpha_{\mathrm{s}} s+\left(J_{0} / J_{\mathrm{r}}\right)\left(\alpha_{\mathrm{s}} / 2 \zeta\right)^{2}} .
\end{aligned}
$$

As can be seen from (29), the above two equations have the same characteristic equation.

$$
s^{2}+2 \frac{J_{0}}{J_{\mathrm{r}}} \zeta \omega_{0} s+\frac{J_{0}}{J_{\mathrm{r}}} \omega_{0}^{2}=0,
$$

where $\omega_{0}=\alpha_{\mathrm{s}} / 2 \zeta$; it is the natural angular frequency of the speed loop.

When the system robustness is analyzed, it is necessary to evaluate the performance of the maximum drop value $\omega_{\mathrm{tm}}$ of the motor speed as the sudden load is applied and the speed error integral value IE in the recovery process.

When there is load disturbance, there are

$$
\begin{aligned}
\omega_{\mathrm{tm}} & \leq \frac{T_{\mathrm{L}}}{k_{\mathrm{vp}}} \\
\mathrm{IE} & =\lim _{t \rightarrow \infty} \int_{0}^{t} \mathscr{L}^{-1}\left(\frac{s}{J_{\mathrm{r}} s^{2}+k_{\mathrm{vp}} s+k_{\mathrm{vi}}} \cdot \frac{T_{\mathrm{L}}}{s}\right) \\
& =\lim _{s \rightarrow 0} s \cdot \frac{1}{s} \cdot \frac{s}{J_{\mathrm{r}} s^{2}+k_{\mathrm{vp}} s+k_{\mathrm{vi}}} \cdot \frac{T_{\mathrm{L}}}{s}=\frac{T_{\mathrm{L}}}{k_{\mathrm{vi}}}
\end{aligned}
$$




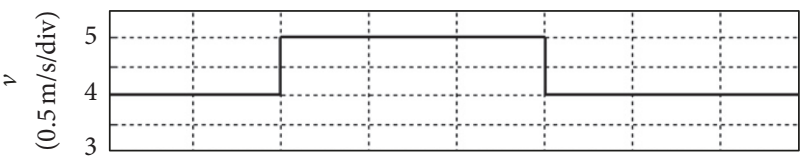

(32 s/div)

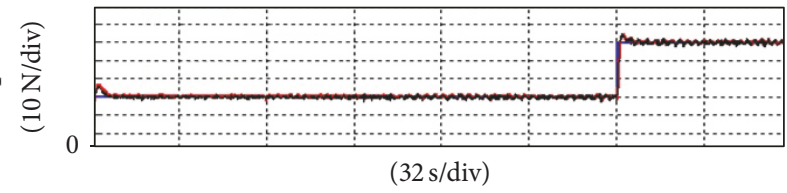

- Observed

- Reference

- Actual
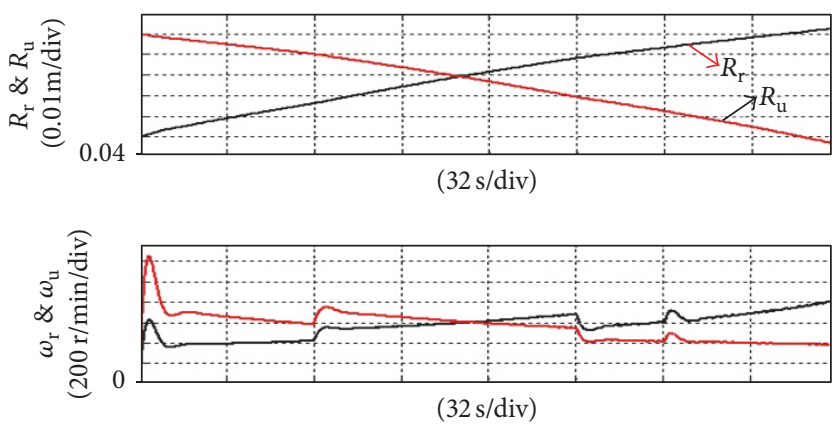

$-\omega_{\mathrm{r}}$

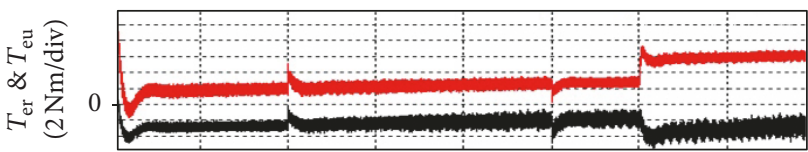

$(32 \mathrm{~s} / \mathrm{div})$

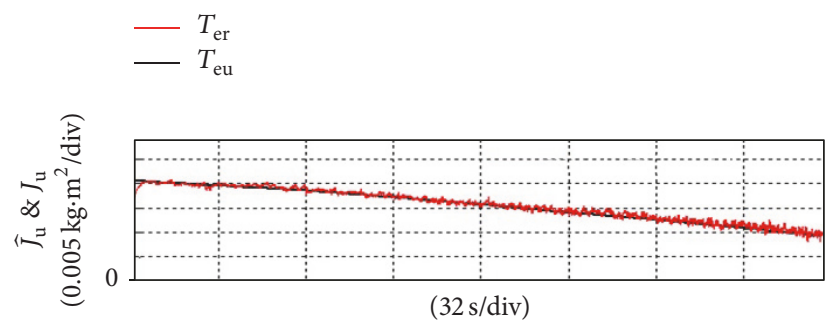

$\widehat{J}_{\mathrm{u}}$
$-J_{\mathrm{u}}$

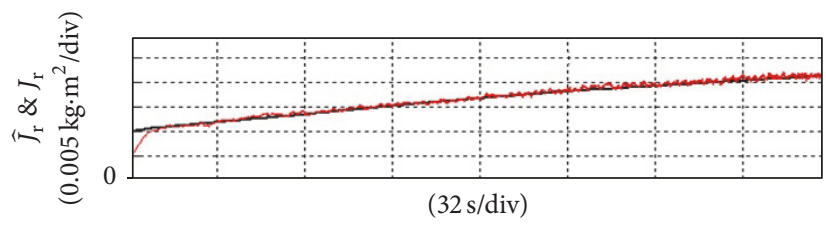

$\hat{J}_{\mathrm{r}}$
$-J_{\mathrm{r}}$

FIgURE 3: The simulation wave of the whole process of rewinding with all characteristics. 
It can be seen from (31) that maximum speed drop value will reduce by improving $k_{\mathrm{vp}}$ and the integral value of speed error in the process of recovery can be lowered by increasing $k_{\mathrm{vi}}$. However, the improvement of $k_{\mathrm{vi}}$ corresponds to the decrease of $\zeta$. This will reduce the robustness of the permanent magnet synchronous motor control system and oscillation can occur in severe cases. Therefore, it is generally necessary to constrain the value of the parameter by the phase margin of the system. The open-loop transfer function of the system $G_{\text {open }}(s)$ is

$$
G_{\mathrm{open}}(s)=\frac{s k_{\mathrm{vp}}+k_{\mathrm{vi}}}{s} \cdot \frac{1}{s J_{\mathrm{r}}} .
$$

Let $\left|G_{\text {open }}(s)\right|=1$; we can get the shear frequency $\omega_{c}$ of the system as follows:

$$
\omega_{\mathrm{c}}=\frac{\alpha_{\mathrm{s}}}{2 \zeta} \sqrt{2 \zeta^{2}+\sqrt{4 \zeta^{4}+1}}
$$

Furthermore, the phase margin $\phi_{\mathrm{m}}$ of the system is as follows:

$$
\begin{aligned}
\phi_{\mathrm{m}} & =\pi+\arg G_{\text {open }}\left(j \omega_{\mathrm{c}}\right) \\
& =\arctan \left(2 \zeta \sqrt{2 \zeta^{2}+\sqrt{4 \zeta^{4}+1}}\right) .
\end{aligned}
$$

In order to ensure the robustness of the permanent magnet synchronous motor control system, we should take $\phi_{\mathrm{m}} \geq 60^{\circ}$; then we can obtain $0.61 \leq \zeta \leq 1$. In this paper, we take $\zeta=0.707$.

Through the analysis above, the following can be obtained: the PI parameter tuning strategy has good adaptability to the permanent closed-loop control system of permanent magnet synchronous motor. The range of $\zeta$ will be determined according to the range of the phase margin firstly and then the speed loop bandwidth value of the speed control system is determined according to the actual needs, for permanent magnet synchronous motor with different moment of inertia. The PI parameter can be set by the magnitude of its moment of inertia. Meanwhile, the PI parameter tuning method above is also applicable to the current loop PI parameter tuning. The derivation process will not be repeated in this paper.

\section{Simulation and Experimental Results Analysis}

4.1. Simulation Results Analysis. In addition, the effectiveness of the observer is also simulated analysis. The simulation parameters are shown in Table 1 except the material inertia. We simulated the larger density material as the motor load, while employing a longer observation time. Figure 3 shows the simulation waveforms of the whole process of the tension control system. The simulation parameters are basically the same as the experimental ones. Only the empty volumes inertia and the full volumes inertia are different, and they are $0.01 \mathrm{~kg} \cdot \mathrm{m}^{2}$ and $0.022 \mathrm{~kg} \cdot \mathrm{m}^{2}$, respectively. The figures from
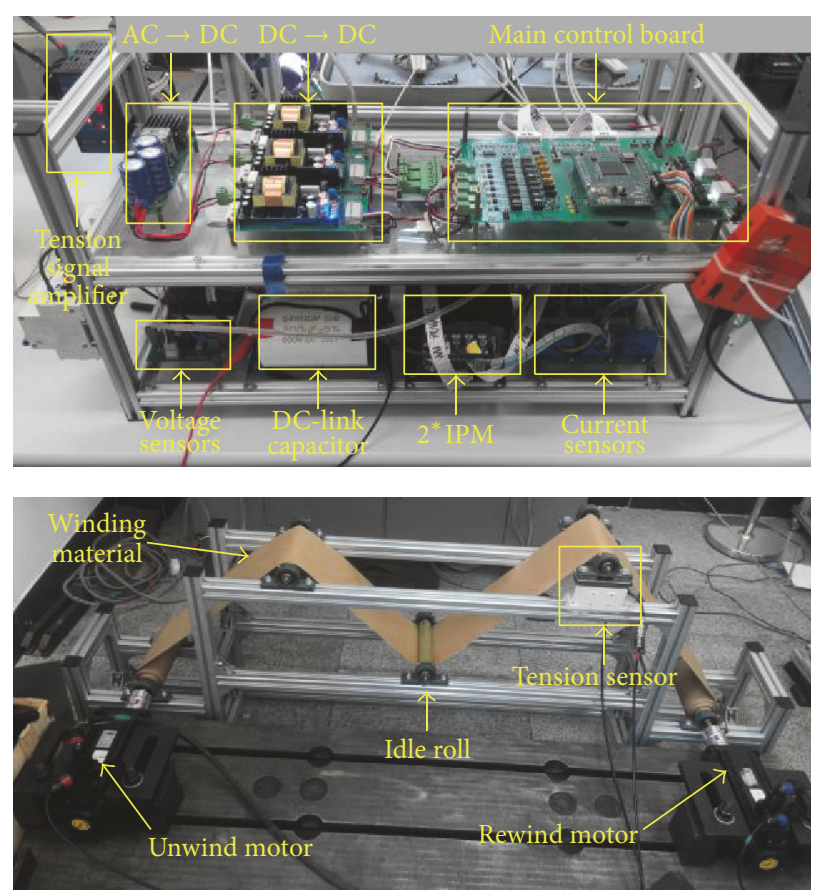

FIGURE 4: Experimental platform.

top to bottom in turn are line speed of reference values, tense values (reference value and actual value, observed value), winding and rewinding roller radius, winding and rewinding motor angular speed, winding and rewinding motor electromagnetic torque, and winding and rewinding roll moment of inertia (actual value and observed value). In simulation, the system linear velocity changed from $4 \mathrm{~m} / \mathrm{s}$ to $5 \mathrm{~m} / \mathrm{s}$ and then to $4 \mathrm{~m} / \mathrm{s}$, and the tension reference value changed from $30 \mathrm{~N}$ to $60 \mathrm{~N}$ suddenly.

It can be seen from the figure that when the linear velocity of the system is constant, with the operation of the system, the winding roller radius increases gradually and roll radius decreases. As the winding and rewinding roll radius changes continuously, the winding of the motor angular velocity decreases and rolling motor angular velocity increases gradually. We can see from the 6th and 7th picture, with the operation of the system, the rotational inertia of the rewinding motor increases gradually, rolling moment of inertia of the motor decreases, and the inertia observer proposed in this paper can estimate the moment of inertia in real time. The analysis results have been added to the revised manuscript.

4.2. Experimental Platform. In order to verify the correctness of the proposed strategy, an experimental platform of tension control system is established shown in Figure 4. The experimental platform consists of a main control board, power circuit, drive circuit, current sensor, voltage sensor, winding material, unwinding motor, rewinding motor, idle rollers, and so on. The DSP applied in the system is TMS320F28335 produced by TI, and the Intelligent Power Module (IPM) is PS21867 produced by Mitsubishi. The 


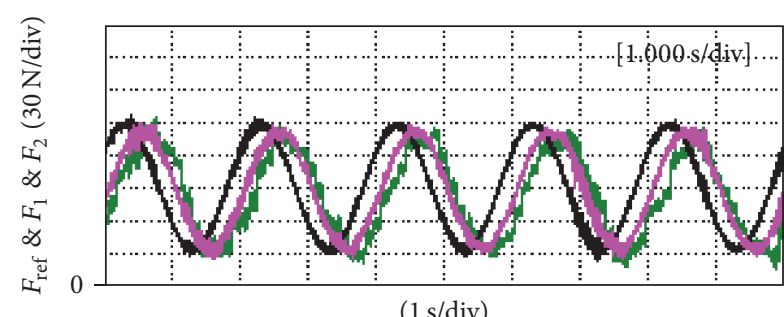

(1 s/div)

\section{- $F_{\text {Ref }}$ (reference) \\ - $F_{2}$ (observed) \\ - $F_{1}$ (measured)}

(a) Sine wave tracking
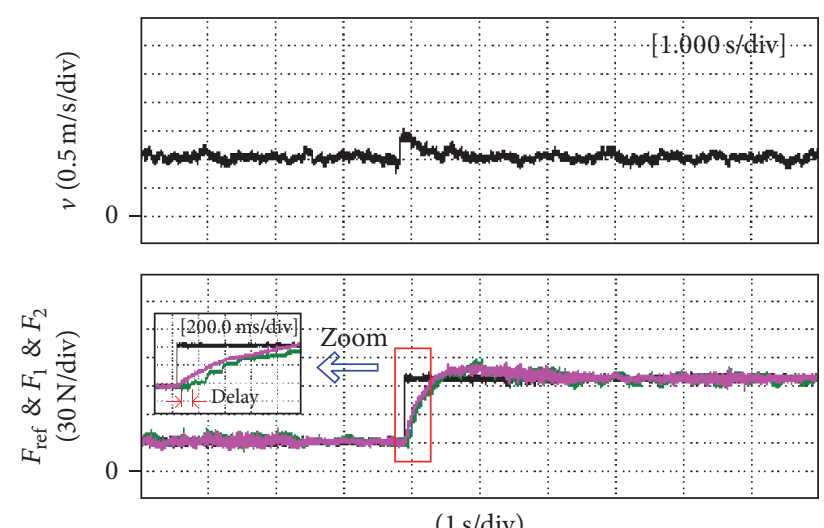

(1 s/div)
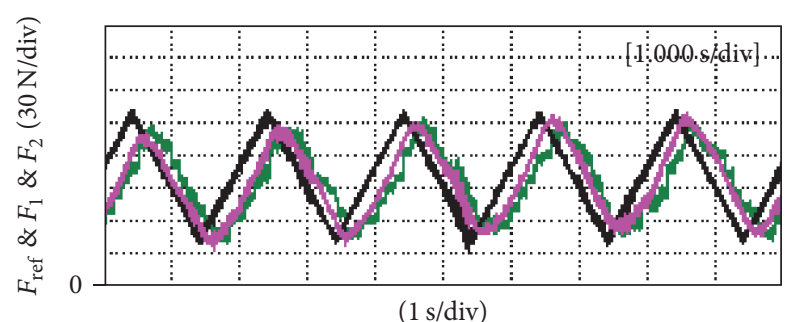

- $F_{\text {Ref }}$ (reference)

$F_{2}$ (observed)

- $F_{1}$ (measured)

(b) Triangle wave tracking
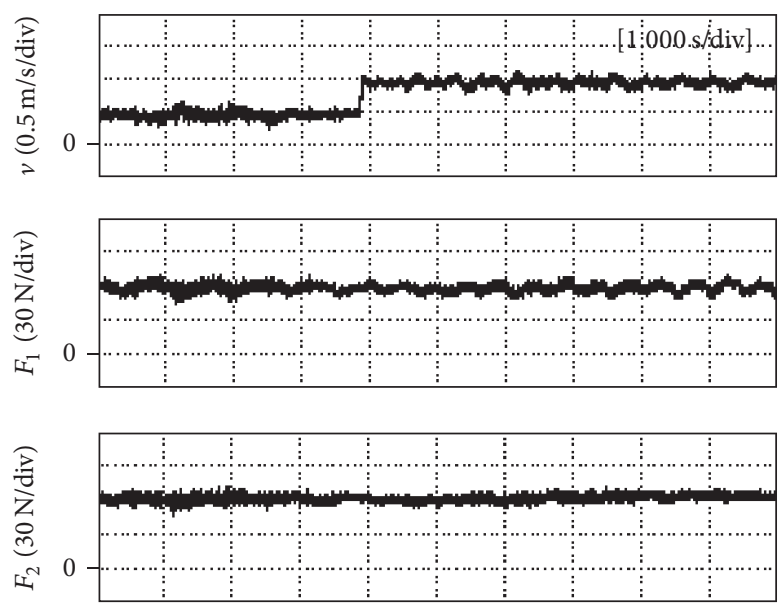

(1 s/div)

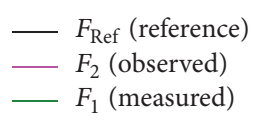

(c) Tension mutation

(d) Velocity mutation

FIGURE 5: Closed-loop control method with tension sensor.

switching frequency of the inverter is $5 \mathrm{kHz}$. Two identical permanent magnet synchronous motors (PMSM) are applied as the rewind and unwind motors in the experiment. The winding material applied in the system is kraft paper. In order to do comparison experiment, a tension sensor is installed, the tension sensor applied in this system is LX-015TD produced by Mitsubishi, and the tension signal amplifier applied in this system is KTC820. The size of the experimental prototype is $2.5 \mathrm{~m} \times 0.6 \mathrm{~m}$, and the detailed mechanical parameters of experimental platform are shown in Table 1.

4.3. Verification Experiment of Tension Identification. Figure 5 shows the experimental waveforms of the direct closedloop control method with tension sensor and Figure 6 shows the method proposed in this paper. Figures 5 and 6 show, respectively, the experimental waveforms under the circumstance that the reference linear velocity remains $1.0 \mathrm{~m} / \mathrm{s}$ and the reference tension changes in the sinusoidal manner, the experimental waveforms under the circumstance that the reference linear velocity remains $1.0 \mathrm{~m} / \mathrm{s}$ and the reference tension changes in the triangular manner, the experimental waveforms under the circumstance that the reference linear velocity remains $1.0 \mathrm{~m} / \mathrm{s}$ and the reference tension changes from $30 \mathrm{~N}$ to $100 \mathrm{~N}$ abruptly, and the experimental waveforms under the same circumstance that the reference tension remains $60 \mathrm{~N}$ and the reference linear velocity changes from $0.5 \mathrm{~m} / \mathrm{s}$ to $1.0 \mathrm{~m} / \mathrm{s}$ abruptly. In the experimental waveforms, $v$ represents the linear velocity and $F_{\text {ref }}, F_{1}$, and $F_{2}$ are, respectively, the reference tension, the tension measured by tension sensor, and the tension observed by the proposed method.

Due to the characteristics of the tension sensor, its output signal is very weak, generally only $200 \mathrm{mV}$. Therefore, usually it takes an amplifier circuit and a filter circuit to process the output signal. The filter time constant used in this experiment is $100 \mathrm{~ms}$. However, some delay of tension sensor signal will be caused inevitably.

As can be seen from Figures 5(a) 5(b) compared to the reference tension $F_{\text {ref }}$, in the tension $F_{1}$ measured by the tension sensor, there exists a delay. And $F_{2}$ is the observed value by the proposed method in the paper. Because tension 
TABLE 1: Mechanical parameters of experimental prototype.

PMSM (rewind motor and unwind motor)

Rated power $P_{\mathrm{N}}$

$\mathrm{kW}$
$\mathrm{r} / \mathrm{min}^{2}$
$\mathrm{~kg} \cdot \mathrm{m}^{2}$
$\Omega$
$\mathrm{mH}$
$\mathrm{N} \cdot \mathrm{m}$
$\mathrm{N} \cdot \mathrm{m} /(\mathrm{rad} / \mathrm{s})$

$\mathrm{m}$

$\mathrm{kg} \cdot \mathrm{m}^{2}$

$\mathrm{m}$

$\mathrm{mm}$

$\mathrm{g}$

$\mathrm{N}$

$\mathrm{V}$

ms
0.00272

0.635

4.025

$0.06 / 0.06$

$0.0004 / 0.0004$

4

$0.05 / 0.1$

$0.00138 / 0.00348$

0.18

0.15

120

150

3

100

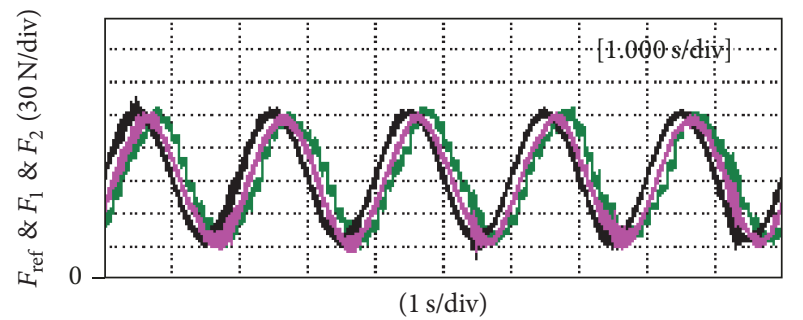

- $F_{\text {Ref }}($ reference)

- $F_{2}$ (observed)

- $F_{1}$ (measured)

(a) Sine wave tracking
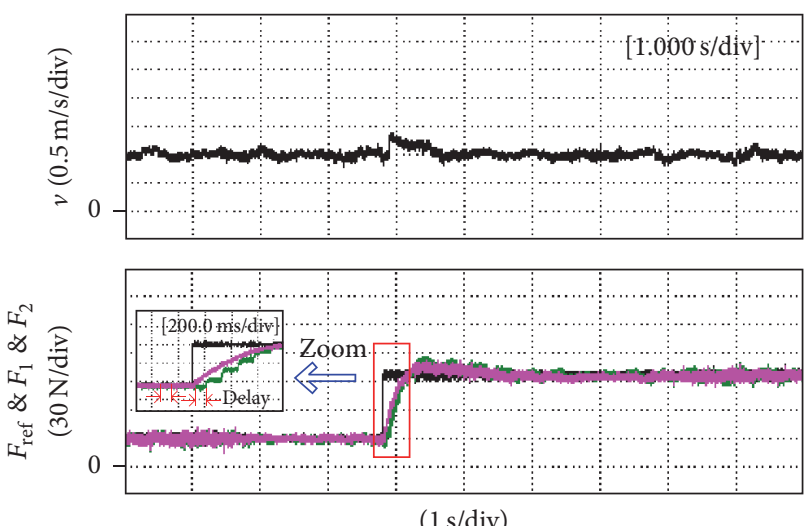

(1 s/div)

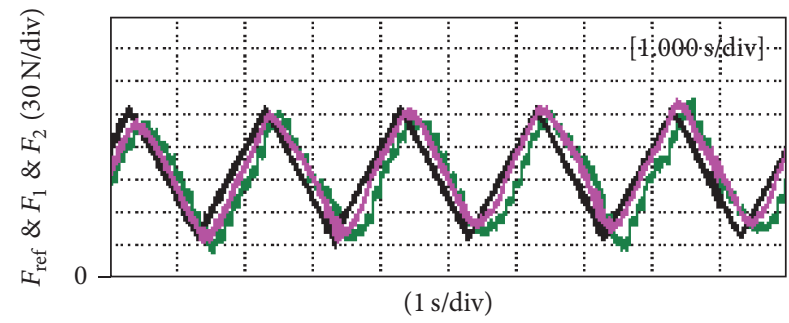

- $F_{\text {Ref }}($ reference $)$

- $F_{2}$ (observed)

- $F_{1}$ (measured)

(b) Triangle wave tracking
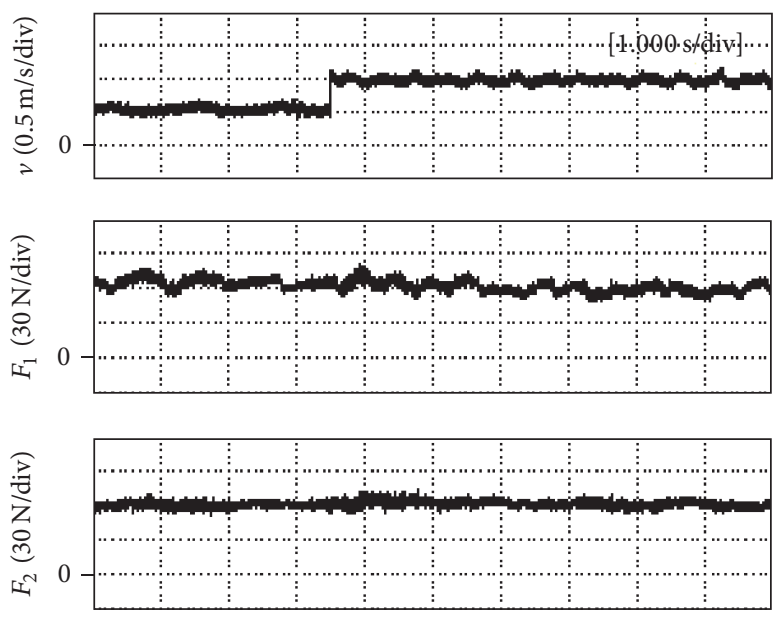

(1 s/div)

- $F_{\text {Ref }}$ (reference)

- $F_{2}$ (observed)

- $F_{1}$ (measured)

(c) Tension mutation

(d) Velocity mutation

FIGURE 6: Closed-loop control method without tension sensor. 


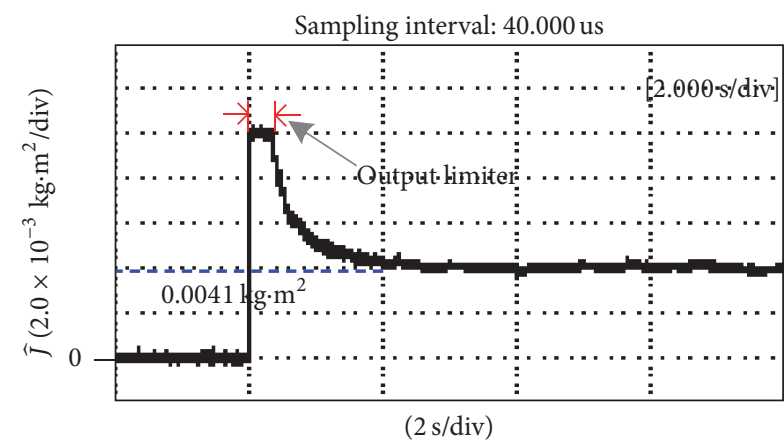

(a)

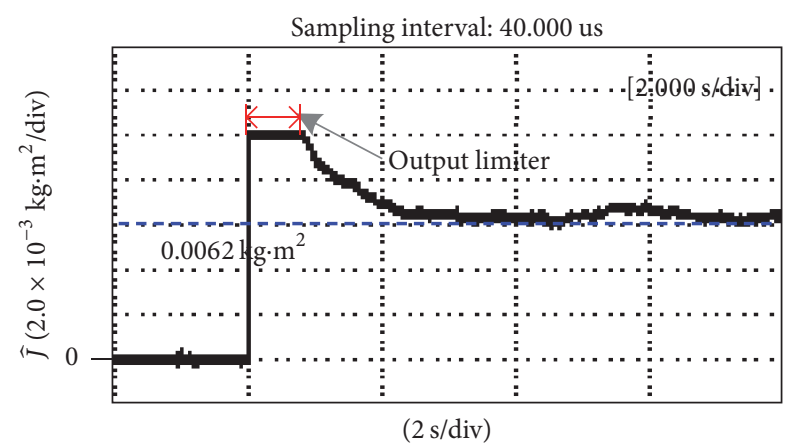

(b)

FIgURE 7: Inertia identification results. (a) Empty volumes; (b) full volumes.

sensor method is used at this time, there is a bigger delay between $F_{\text {ref }}$ and $F_{2}$. For the tension system, it can be seen that control method with tension sensor will be difficult to meet the requirements for many high-speed applications. However, from Figures 6(a) 6(b), there is a smaller delay between $F_{\text {ref }}$ and $F_{2}$, compared to Figures 5(a) 5(b).

Thus, from Figures 5(c) and 6(c), when the reference tension changes from $30 \mathrm{~N}$ to $100 \mathrm{~N}$ abruptly (tension mutation), the linear velocity change without tension sensor control method is smaller than that with tension sensor. And the tension observed by the proposed method can track the reference tension excellently. From Figures 5(d) and 6(d), when the reference linear velocity changes from $0.5 \mathrm{~m} / \mathrm{s}$ to $1.0 \mathrm{~m} / \mathrm{s}$ abruptly (velocity mutation), it can be seen that the observed tension by the proposed method can track the reference tension precisely even if the linear velocity changes abruptly. In summary, the proposed method can achieve nearly the same control performance as the direct closed-loop control method with tension sensor.

4.4. Verification Experiments of Inertia Identification and Adaptive Parameter of the Controller. The total inertia on the rewind motor side consists of the inertia of motor armature, driving shaft, the winding material, and so on. Among them, the inertias of motor armature and driving shaft are constants, while the inertia of winding material is time-varying, because the material is continuously released into the process. After calculation, the theoretical values of inertia when the rewind roll is empty and full are $0.0041 \mathrm{~kg} \cdot \mathrm{m}^{2}$ and $0.0062 \mathrm{~kg} \cdot \mathrm{m}^{2}$, respectively. Landau algorithm adaptive gain $\gamma$ is 0.05 in the experiment. Because the identification process of inertia involves the division calculation, to prevent the arithmetic overflow in the early operation, the output limiter is adopted. As can be seen from Figure 7, the proposed identification method can converge to the theoretical value of inertia within two seconds.

In order to verify the parameters self-adaptive function of the proposed method, a series of comparative experiments are conducted. In some large industrial applications such as the steel rolling production line, the inertia changes generally substantially. It is necessary to correct the parameters of speed controllers based on the inertia. However, due to the limitations of the experimental platform in this paper, the inertia changes very slowly, and the effect is difficult to observe in one set of experiments. Therefore, in order to observe the effect of the algorithm clearly, the experiments are carried out in two stages that the unwind roll is empty and full, respectively. In the two cases of unchanged parameters and adaptive parameters, the reference linear velocity remains $1.0 \mathrm{~m} / \mathrm{s}$ and the reference tension changes from $30 \mathrm{~N}$ to $110 \mathrm{~N}$. Moreover, the reference tension remains $60 \mathrm{~N}$, and the reference linear velocity changes from $0.5 \mathrm{~m} / \mathrm{s}$ to $1.0 \mathrm{~m} / \mathrm{s}$. Experimental waveforms are shown in Figure 6. Since the observed inertias have yet to converge to the actual value during the start-up phase of the motor, the algorithm of adaptive parameters is not applied until the system goes through the start-up phase and reaches the steady state.

Figure 8(a) shows that since the PI parameters of speed controller are not self-adaptive in case of inertia variation, when the parameters are unchanged, a slight overshoot is generated when the unwind roll is in full volume. However, in Figure $8(\mathrm{~b})$, because the parameters adapt themselves to the inertia variation, the waveform is basically the same whether the rewind roll is empty or full. Figures 8(c) and 8(d) show that when the unwind roll is empty, the changes of velocity have the same influence on tension whether the speed controller parameters are unchanged or adaptive. However, when the unwind roll is full, velocity changes have greater influence on the tension when the controller parameters are unchanged than when the controller parameters are adaptive, which demonstrates the effectiveness of the proposed method.

\section{Conclusion}

This paper proposes a novel tension control strategy which needs no additional hardware. A sensorless tension control strategy only using the speed signal obtained by the encoder and the current signal of the rewind motor is realized. The unwind motor is used to set the linear velocity, and the rewind motor is used to control the tension. With respect to the variation of the inertias caused by the radii of rewind and unwind rolls, Landau discrete adaptive algorithm is adopted in this paper, which overcomes the shortcomings of the conventional method to estimate the inertia that the 

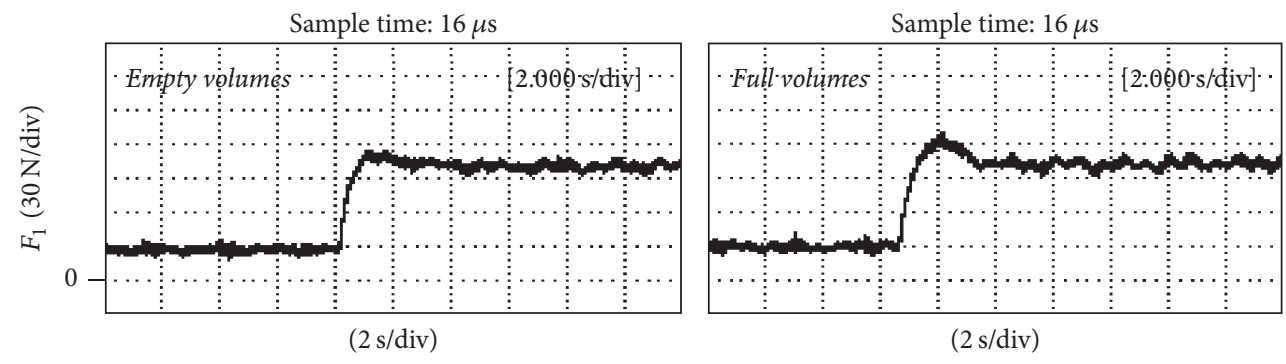

(a)
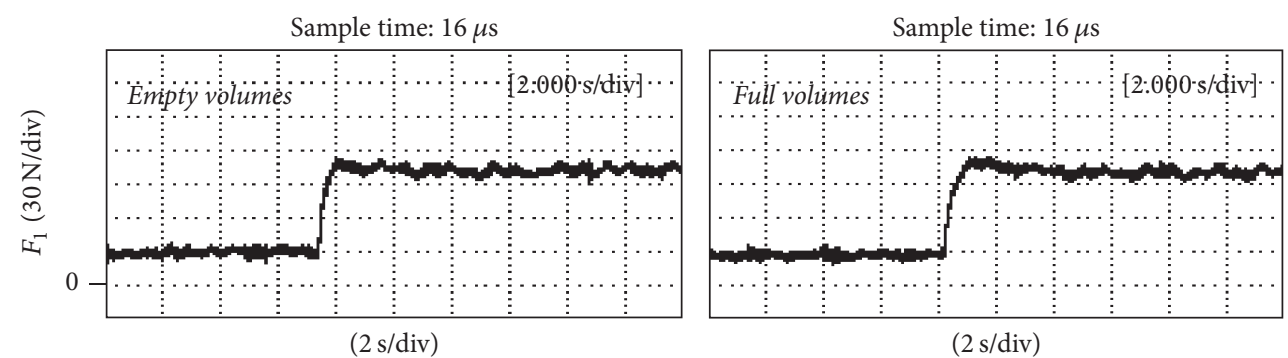

(b)
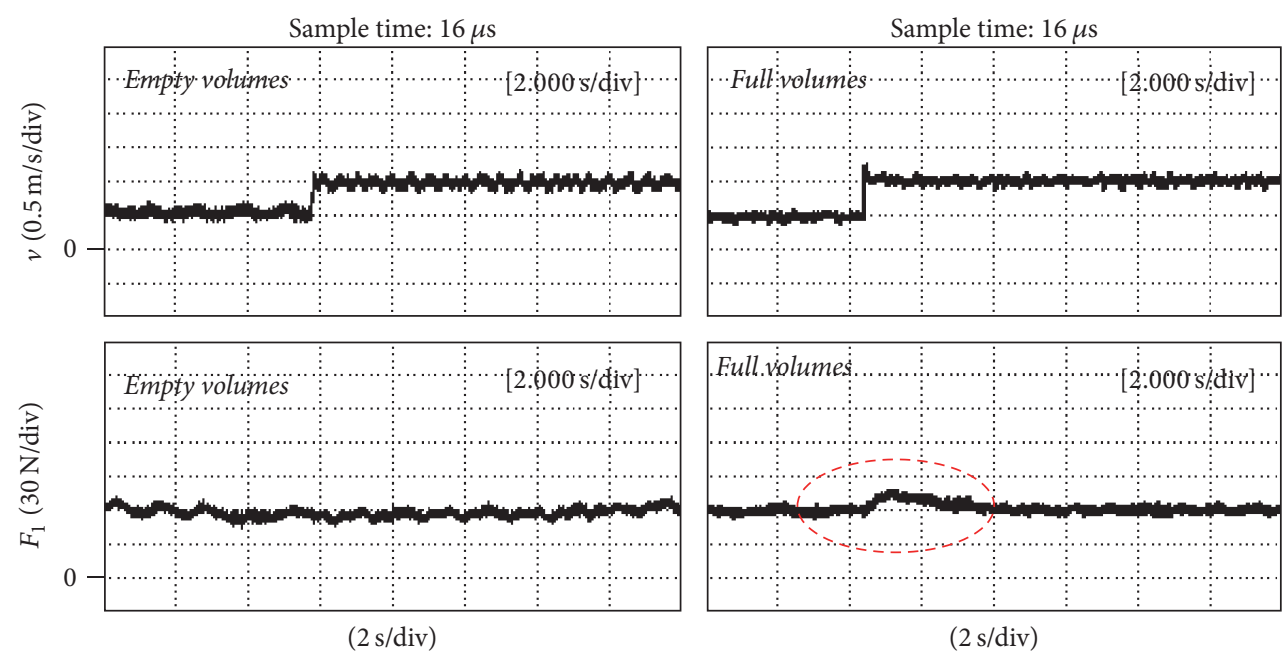

(c)
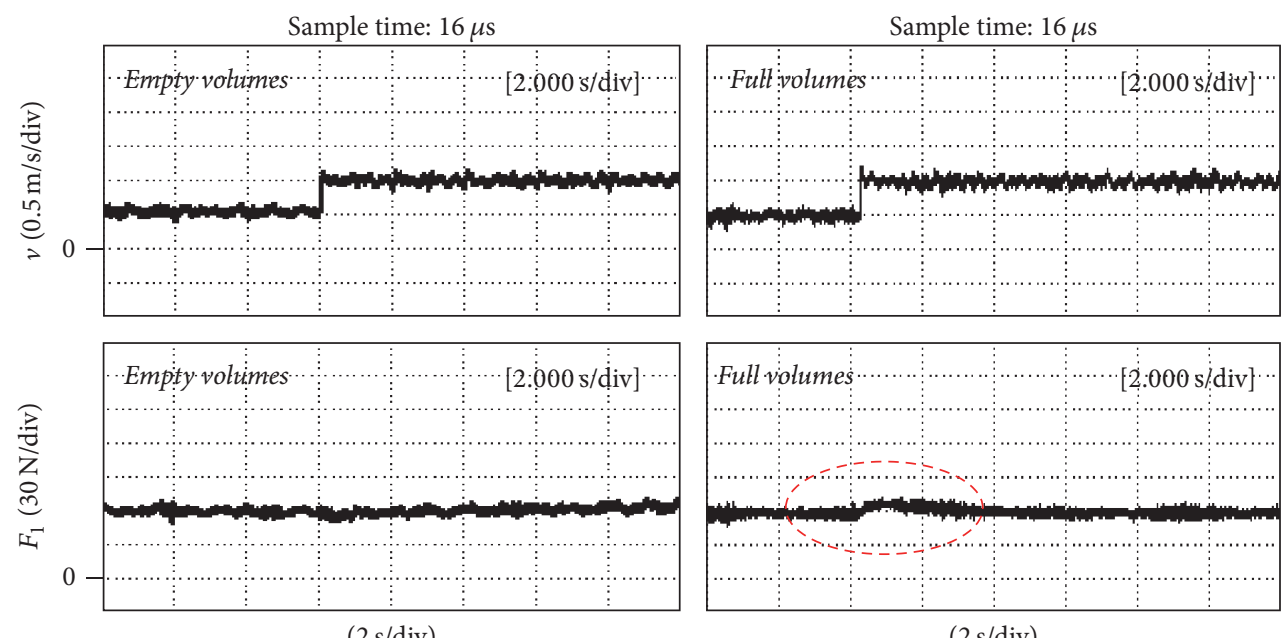

(d)

FIGURE 8: Adaptive controller parameters experiment when the tension and velocity mutation. (a) Tension mutation, parameters unchanged; (b) tension mutation, adaptive parameters; (c) velocity mutation, parameters unchanged; (d) velocity mutation, adaptive parameters. 
knowledge of the density, thickness, and other information of the winding material is required. Moreover, the observed inertia is used to adjust the parameters of speed controllers online, which enables the tension control system to still maintain good dynamic performance even if the inertia changes dramatically. Experimental results demonstrate the feasibility of the program. The tension sensor is replaced by a tension observer in this paper, which reduces the cost, solves the problems that tension sensor cannot be ins $\mathrm{f}$ matalled in some special occasions, and avoids the quality degradation caused by the delay of sensors. In addition, the structure of the method is simple and easy to implement. Therefore, the proposed method proves to be of practical value in industrial applications.

\section{Conflicts of Interest}

The authors declare that there are no conflicts of interest regarding the publication of this paper.

\section{Acknowledgments}

This work was partially supported by National Natural Science Foundation of China (no. 51377121 and no. 51407127).

\section{References}

[1] N. Nevaranta, M. Niemela, J. Pyrhonen, O. Pyrhonen, and T. Lindh, "Indirect tension control method for an intermittent web transport system," in Proceedings of the 15th International Power Electronics and Motion Control Conference and Exposition, EPEPEMC 2012 ECCE Europe, Novi Sad, Serbia, September 2012.

[2] C. Wang, Y. Wang, R. Yang, and H. Lu, "Research on precision tension control system based on neural network," IEEE Transactions on Industrial Electronics, vol. 51, no. 2, pp. 381-386, 2004.

[3] T. Shi, H. Liu, Q. Geng, and C. Xia, "Improved relative coupling control structure for multi-motor speed synchronous driving system," IET Electric Power Applications, vol. 10, no. 6, pp. 451457, 2016.

[4] H. Koç, D. Knittel, M. De Mathelin, and G. Abba, "Modeling and robust control of winding systems for elastic webs," IEEE Transactions on Control Systems Technology, vol. 10, no. 2, pp. 197-208, 2002.

[5] C. Lee and K. Shin, "A Study on the Taper Tension Control Considering Telescoping in the Winding System," in Proceedings of the 2007 IEEE Industry Applications Annual Meeting, pp. 398403, New Orleans, LA, USA, September 2007.

[6] F. He and Q. Wang, "Compensation and fuzzy control of tension in strip winding control system," in Proceedings of the 2012 7th IEEE Conference on Industrial Electronics and Applications, ICIEA 2012, pp. 22-27, Singapore, July 2012.

[7] S. Zhang, W. He, and S. Sam Ge, "Modeling and control of a nonuniform vibrating string under spatiotemporally varying tension and disturbance," IEEE/ASME Transactions on Mechatronics, vol. 17, no. 6, pp. 1196-1203, 2012.

[8] M. A. Valenzuela, J. M. Bentley, and R. D. Lorenz, "Sensorless tension control in paper machines," IEEE Transactions on Industry Applications, vol. 39, no. 2, pp. 294-304, 2003.
[9] R. Carrasco and M. A. Valenzuela, "Tension control of a twodrum winder using paper tension estimation," IEEE Transactions on Industry Applications, vol. 42, no. 2, pp. 618-628, 2006.

[10] M. A. Valenzuela, R. Carrasco, and D. Sbarbaro, "Robust sheet tension estimation for paper winders," IEEE Transactions on Industry Applications, vol. 44, no. 6, pp. 1937-1949, 2008.

[11] G. Ramírez, R. D. Lorenz, and M. A. Valenzuela, "Observerbased estimation of modulus of elasticity for papermaking process," IEEE Transactions on Industry Applications, vol. 50, no. 3, pp. 1678-1686, 2014.

[12] A. F. Lynch, S. A. Bortoff, and K. Röbenack, "Nonlinear tension observers for web machines," Automatica, vol. 40, no. 9, pp. 1517-1524, 2004.

[13] S.-H. Song and S.-K. Sul, "A new tension controller for continuous strip processing line," IEEE Transactions on Industry Applications, vol. 36, no. 2, pp. 633-639, 2000.

[14] S.-H. Song and S.-K. Sul, "Design and control of multispan tension simulator," IEEE Transactions on Industry Applications, vol. 36, no. 2, pp. 640-648, 2000.

[15] N. R. Abjadi, J. Soltani, J. Askari, and G. R. Arab Markadeh, "Nonlinear sliding-mode control of a multi-motor webwinding system without tension sensor," IET Control Theory \& Applications, vol. 3, no. 4, pp. 419-427, 2009.

[16] K. Zhang, B. Jiang, X.-G. Yan, and Z. Mao, "Sliding mode observer based incipient sensor fault detection with application to high-speed railway traction device," ISA Transactions ${ }^{\circledR}$, vol. 63, pp. 49-59, 2016.

[17] M. Mohamed, X.-G. Yan, S. K. Spurgeon, and B. Jiang, "Robust sliding-mode observers for large-scale systems with application to a multimachine power system," IET Control Theory \& Applications, vol. 11, no. 8, pp. 1307-1315, 2017.

[18] D. Shin, W. Kim, and Y. Lee, "Observer based nonlinear tension control for multi motor wire winding system," in Proceedings of the in Proceeds of 12th International Conference on Automation and Systems (ICCAS), pp. 1333-1336, JeJu Island, Oct 2012.

[19] Q. Liu, T. Chai, H. Wang, and S.-Z. J. Qin, "Data-based hybrid tension estimation and fault diagnosis of cold rolling continuous annealing processes," IEEE Transactions on Neural Networks and Learning Systems, vol. 22, no. 12, pp. 2284-2295, 2011.

[20] P. R. Pagilla, R. V. Dwivedula, and N. B. Siraskar, "A decentralized model reference adaptive controller for large-scale systems," IEEE/ASME Transactions on Mechatronics, vol. 12, no. 2, pp. 154-163, 2007.

[21] P. R. Pagilla, N. B. Siraskar, and R. V. Dwivedula, "Decentralized control of web processing lines," IEEE Transactions on Control Systems Technology, vol. 15, no. 1, pp. 106-117, 2005.

[22] R. Bettendorf, "Winder software testing with real-time dynamic simulation," IEEE Transactions on Industrial Electronics, vol. 52, no. 2, pp. 489-498, 2005.

[23] B. Zhou and G. Duan, "Solutions to the positive real control problem for linear systems via reduced-order observer," in Proceedings of the 7th World Congress on Intelligent Control and Automation, WCICA'08, pp. 4623-4627, Chongqing, China, June 2008.

[24] Y. Guo, L. Huang, and M. Muramatsu, "Research on inertia identification and auto-tuning of speed controller for AC servo system," in Proceedings of the Power Conversion ConferenceOsaka 2002, PCC-Osaka 2002, pp. 896-901, Osaka, Japan, April 2002.

[25] I. D. Landau, Adaptive Control, Springer, Berlin, Germany, 1998. 
[26] L. Harnefors, S. E. Saarakkala, and M. Hinkkanen, "Speed control of electrical drives using classical control methods," IEEE Transactions on Industry Applications, vol. 49, no. 2, pp. 889-898, 2013.

[27] C. Xia, B. Ji, T. Shi, and Y. Yan, “Two-degree-of-freedom proportional integral speed control of electrical drives with Kalmanfilter-based speed estimation," IET Electric Power Applications, vol. 10, no. 1, pp. 18-24, 2015. 


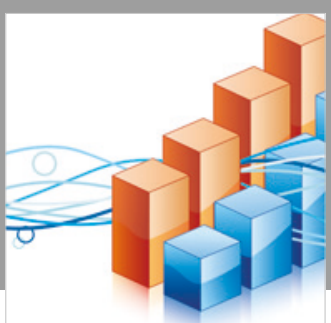

Advances in

Operations Research

\section{-n-m}
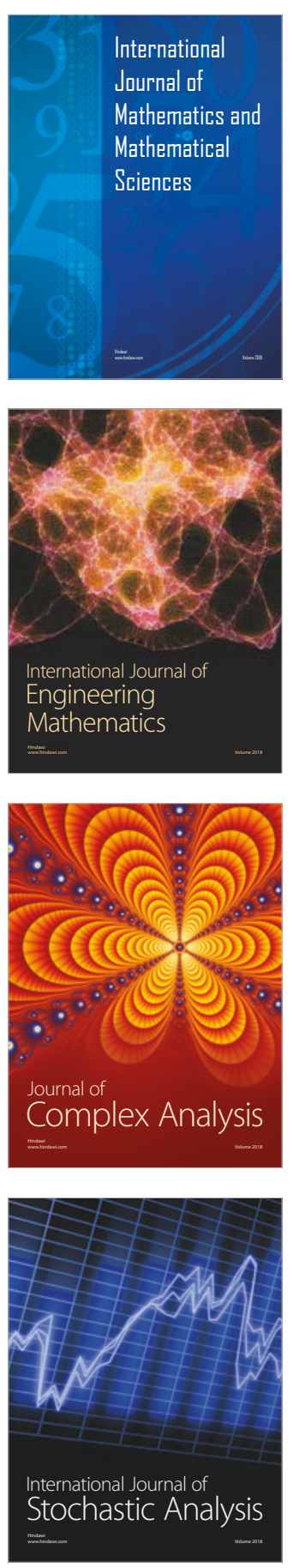
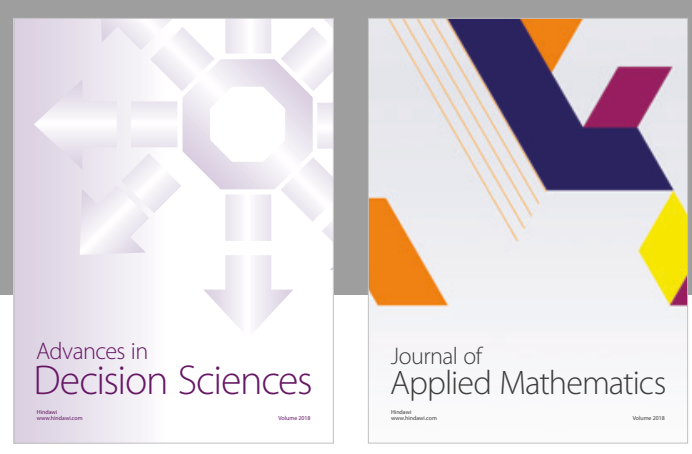

Journal of

Applied Mathematics
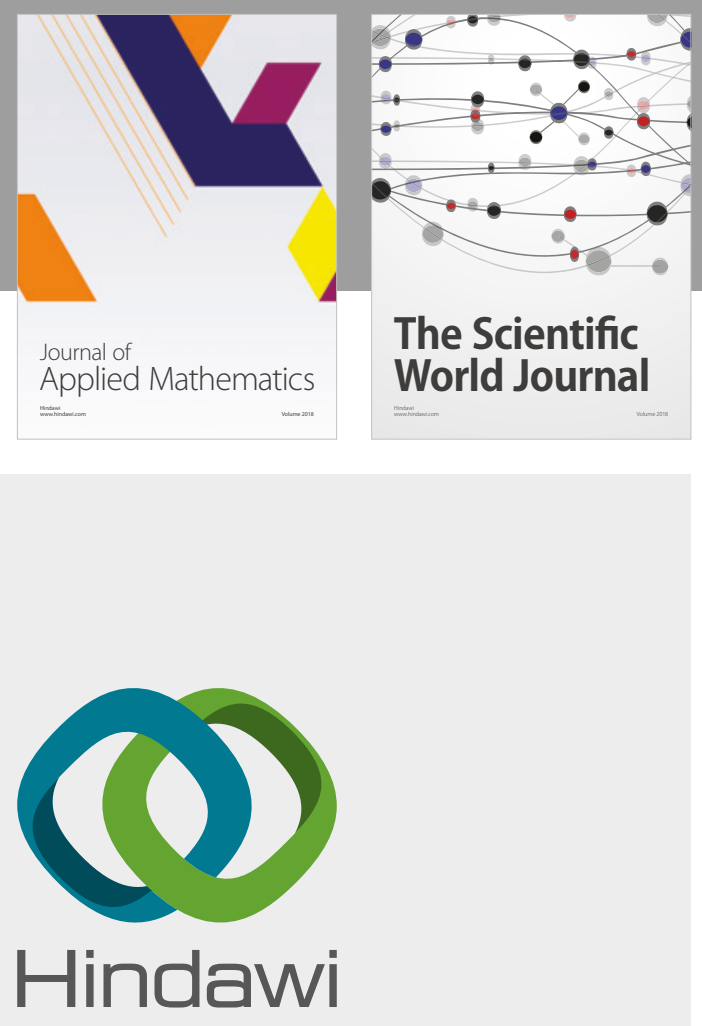

Submit your manuscripts at

www.hindawi.com

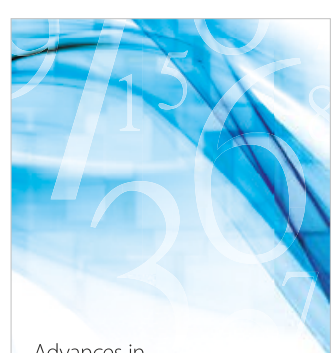

Advances in
Numerical Analysis
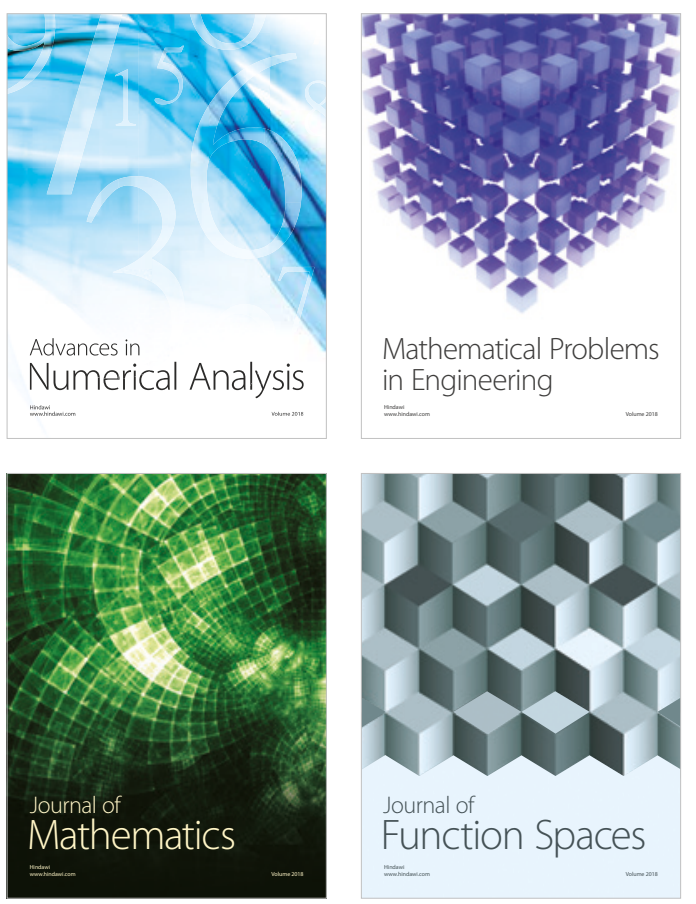

Mathematical Problems in Engineering

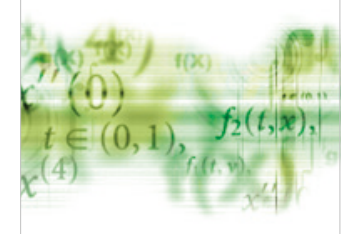

International Journal of

Differential Equations

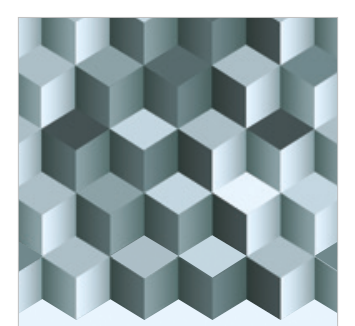

Journal of

Function Spaces

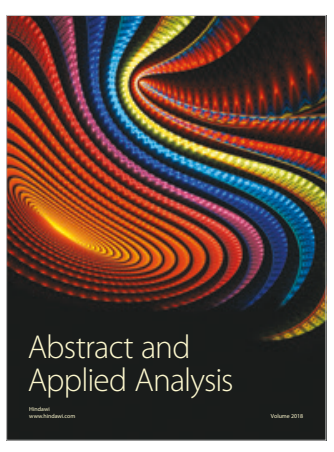

The Scientific

World Journal

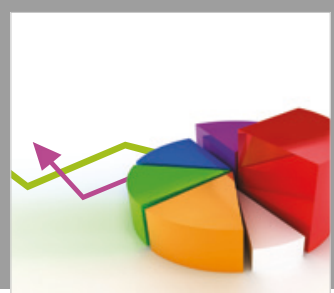

Journal of

Probability and Statistics
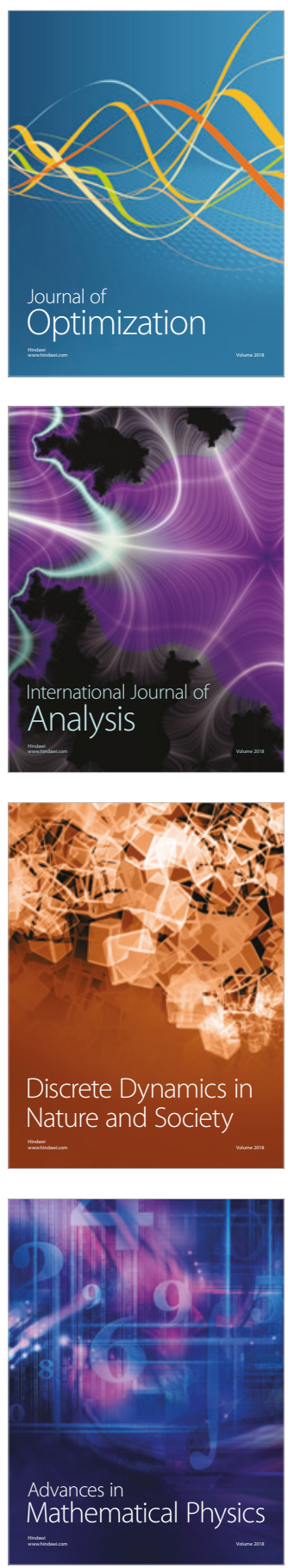